\title{
The Experiences of Emergency-Remote Teaching Via Zoom: The Case of Natural-Science Teachers Handling of Deaf/Hard-of-Hearing Learners in South Africa
}

\author{
Olufemi Timothy Adigun \\ University of Zululand, KwaDlangeZwa, South Africa
}

\begin{abstract}
Information regarding the e-teaching of science subjects to learners who are deaf or hard-of-hearing (LDHH) is somewhat scarce in the existing literature. The COVID-19 pandemic has, however, compelled all to adopt Information-Communication Technologies (ICTs) for teaching during this period. Lamentably, previous studies have advanced some of the challenges associated with teaching science to LDHH during online-science classes. While the pandemic has compelled remote teaching, there is a paucity of research evidence on the experiences of natural-science teachers handling of LDHH learners in emergencyremote teaching via Zoom. Therefore, anchored on the Use-andGratification Theory, this study has explored the emergency-remote teaching of natural sciences to deaf learners via Zoom during the pandemic. This study employed a qualitative research design, with seven natural science teachers as participants. The data were gathered via a semi-structured Zoom interview; and they were analysed by using thematic-content analysis. The findings revealed that while the participants appreciated the uninterrupted-learning model presented by ICTs, they had relatively awful experiences when teaching naturalscience subjects to LDHH via Zoom, due to inadequate organisational and individual preparedness, as well as to limited two-way teacherlearners' communication and interactions. Based on the findings, the appropriate recommendations were made for both policy and practice.
\end{abstract}

Keywords: coronavirus disease; learners who are deaf/hard-of-hearing; natural sciences; teachers; Zoom

\section{Introduction}

The emergence of the coronavirus disease in 2019 (COVID-19) has become a global public-health crisis. COVID-19 has had a negative and brutal impact, not only on global health, but also on economic activities, education, and the psychosocial wellbeing of people around the world, regardless of disabilities, gender, ethnicity, or national boundaries. Due to COVID-19 and its associated threat to 
the lives of people (Maphalala \& Adigun, 2021), nations across the world have initiated several levels of lockdown, in order to contain the community transmission of the virus. A series of lockdown measures caused the interruption of face-to-face teaching and learning models, which predominantly characterise the educational systems in sub-Saharan African nations, with South Africa being no exception.

To prevent community transmission of COVID-19, educational institutions in South Africa resolved to continue teaching and learning activities via online modes by using various e-learning platforms and video-conferencing technologies (VCTs) (Tanga, Ndhlovu \& Tanga, 2020). However, many South African educational institutions and staff members - especially the teachers of learners, who are deaf or hard-of-hearing (LDHH) in various secondary, special or inclusive schools - were not adequately prepared for teaching via various elearning platforms. LDHH refers to individuals who, without amplification devices, such as hearing aids, are insensitive to sound stimuli through the organ of hearing (Adigun, 2020; Pizzo, 2016; Madhesh, 2021).

COVID-19 has compelled all teachers, including teachers of LDHH, to adopt Internet-enabled information communication technologies (ICTs) for the emergency-remote teaching of school subjects, including the natural sciences. Interestingly, since the emergence of COVID-19, a plethora of research evidence has become available on the teaching and learning approaches adopted during the various phases of lockdown in South Africa and in many other sub-Saharan African nations (Tanga et al., 2020). These studies have largely explored the various dimensions of e-learning and its implications on learning outcomes. However, a paucity of research evidence exists on the issues surrounding eteaching during this challenging time of COVID-19, especially regarding the eteaching of natural sciences to LDHH. To bridge the existing research gap, this current study explored the issues associated with the emergency-remote teaching of the natural sciences to LDHH by using Zoom during the lockdown.

\section{The Literature review}

Engagement in sciences may foster interest in the sciences (James et al., 2019; Jita \& Munje, 2020). Regardless of hearing acuity, interest and engagement in sciences can provide learners with opportunities that foster their curiosity about the natural environment, thereby enabling them to understand scientific processes and actively participate in processes that sustain the natural environment. To promote scientific knowledge, post-apartheid South Africa developed the Curriculum and Assessment Policy Statement (CAPS) (South African Department of Basic Education, 2011), which extensively caters for scientific concepts, such as the natural sciences. As maintained by Sooryamoorthy (2020), the natural sciences as a subject encompass issues that touch on several aspects of, for example, astronomy, ecology, geography, mathematics, and water resources. Lamentably, studies in the last decade have criticized the pedagogical approaches to teaching the natural sciences (Adigun \& Nzima, 2020; James et al., 2019). Prior to the emergence of COVID-19, critics encouraged the infusion, application, and use of 
ICTs in the teaching of scientific concepts to learners, particularly those with learning challenges.

Adigun (2017) suggested that e-learning, or a blended-educational approach for $\mathrm{LDHH}$, could further stimulate their interest in the natural sciences. LDHH refers to individuals who, without amplification devices, such as hearing aids, are insensitive to sound stimuli through the organ of hearing (Adigun, 2020; Pizzo, 2016;). Without amplification, LDHH may significantly lack the capabilities required to respond to auditory-verbal stimuli, which may negatively influence their engagement and performance in science education. Regardless of the degree of loss in the sense of hearing and/or the onset of deafness (pre- or post-lingual before or after acquisition of speech and languages), $\mathrm{LDHH}$ are bound by similar cultural and visual language identities.

They communicate largely through sign language, and in conjunction with other visual modes of communication. Unfortunately, LDHH have greater potential to miss out on accidental learning. Furthermore, due to their hearing conditions and the associated psychological and social challenges (Adigun, 2020; Pizzo, 2016), LDHH experience uneven academic treatment, with a reduced expectation of their strength for science engagement and unequivocal science achievement (Adigun, 2020).

Some studies have expressed the dissatisfaction of stakeholders (for example, parents, teachers, and education officers) regarding the under-representation of $\mathrm{LDHH}$ in the sciences, as well as the abysmal performance of LDHH in science subjects (Adigun \& Nzima, 2021; Ogundiran \& Olaosun, 2013). Regardless of past reports on science engagement by $\mathrm{LDHH}$, the current global situation, due to COVID-19, might have further stimulated the interest of many LDHH to undertake science instruction. This perceived interest may be due to the scientific nature and the characteristics of COVID-19, as it has affected human interactions, co-existence, and teaching and learning activities; and it has necessitated the use of emergency-remote teaching.

Interestingly, in recent times, educational researchers have expended much research effort in exploring the various opportunities provided by the Internet for the continuation of teaching and learning activities during the pandemic. Various forms of Internet-enabled video-conferencing technologies (VCTs), such as Blackboard, Duo, FaceTime, Google MS Teams, Webex, Zoom, have dominated the field of education in recent times (Mpungose, 2020).

Since the emergence of COVID-19, Zoom has gained much recognition, as an example of a VCT, and its usage among educators has become more popular. According to Mpungose (2020) and Osuagwu et al. (2017), Zoom is an Internetenabled audio-visual technology that allows for virtual pedagogical content dissemination and easy, collaborative and seamlessly uninterrupted teaching and learning interactions between teachers and learners at disparate locations. 
Remarkably, teachers' preferences for the use of Zoom in emergency-remote teaching during the lockdown was due to its potential for both synchronous and asynchronous modes of instructional delivery (Alsadoon \& Turkestani, 2020; Mukhopadhyay \& Mukhopadhyay, 2020). As posited by Alsadoon and Turkestani (2020), Zoom provides a synchronous teaching environment, which provides deaf learners with a sense of social presence, and an asynchronous teaching facility, whereby learners can revisit recorded teaching, messages and files shared.

In their study, Alshawabkeh et al. (2021) noted that teaching via Zoom has the capacity to enhance collaborative teaching and learning activities, as well as to provide improved real-time feedback from participants. In addition, teaching via Zoom has increased students' satisfaction during various teaching and learning sessions. As further indicated by Lynn et al. (2020) in their study, students were able to see live commands for scientific processes and the usage of equipment and tools. Other studies, for instance those of Maphalala and Adigun (2021), Alshawabkeh et al. (2021), and Schmitt and Eilderts (2018), alluded to the fact that the application of ICTs, especially those with provisions for real-time audio-visual communication, have the capacity to provide spontaneous feedback to learners.

The application of Internet-enabled real-time VCTs in the education of deaf learners has the capacity to accommodate varied learning styles, irrespective of distance, geographical location, and time zones (Adigun \& Nzima, 2020; Alshawabkeh et al. 2021). Unfortunately, despite the emphasis on the need for adoption and the use of ICTs and VCTs in the education of deaf learners (Adigun, 2020; Alshawabkeh et al., 2021), recent evidence has revealed the difficulties and limitations associated with the application of ICT/VCTs in the education of deaf learners. For instance, some studies showed that digital teaching, especially for deaf learners, could aggravate both learning fatigue and the lack of required teacher-learner and learner-learner relationships (Alsadoon \& Turkestani, 2020; Lynn et al., 2020).

Lamentably, during web-teaching, Schmitt and Eilderts (2018) recorded that there was a greater tendency for the loss of teacher-learners' connectedness, and learners had a greater potential for getting bored, due to the long hours of their eyes' fixation on a computer screen. In other words, deaf learners have enormous cognitive and sensory responsibilities to cope with during e-teaching and elearning activities. While online teachers may share different educational materials in different forms (for example, PowerPoint, moving or still images, and Word documents), instructional deliveries that incorporate sign-language interpreters during teaching activities via Zoom, may lead to additional cognitive and sensory overload for deaf learners. Previous studies by Al Atiyat (2018) and Kanellopoulou et al. (2019) revealed that a high cognitive overload is inevitable when teachers use different media and material concurrently during synchronous communication and in the teaching of young learners.

Assertively, Al Atiyat (2018) states that deaf learners may experience high cognitive loads, when multimedia are not carefully and strategically infused by 
teachers. Al Atiyat (2018) further alluded to the fact that complexities in learning may be predisposed by the characterised experiences of delayed language acquisition, and inefficient reading, as well as comprehension skills.

Using a wide array of materials for teaching via VCTs has the potential to significantly enhance the learning experiences of LDHH (Adigun, 2020; Lynn et al., 2020); but as is currently being witnessed during this COVID-19 pandemic, many online instructors of LDHH lack the required e-learning pedagogical skills needed for teaching during emergency-remote teaching (Alsadoon \& Turkestani, 2020; Lynn et al., 2020). According to Kanellopoulou et al. (2019), teachers, especially those who are novices to teaching via VCTs, experience challenges with the use of the appropriate learning materials required. The fact remains that while these teachers can use instructional materials effectively during face-to-face teaching, the majority lack the capacity and the technical know-how needed for the application and usage during digital teaching (Adigun \& Nzima, 2020).

Regardless of the technology-use efficacy of teachers, Tanga et al. (2020) aver that teaching via Internet-enabled synchronous models or VCTs requires more preparation time from teachers than is expected for the traditional (face-to-face) model of teaching. As expressed by Lazzari and Baroni (2020), the foregoing assertion may be due to teachers' quests for quality audio-visual instructional material that would suit the learning needs of all learners, who are not within their physical range. According to Pappas et al. (2018), teachers of deaf learners are faced with enormous challenges regarding the need to provide real-time captioning for learners during VCTs-enabled teaching.

Consequently, there is a need for teachers employing e-teaching to search patiently for, or to create instructional materials that LDHH might find interesting, motivating and stimulating, and which should arouse curiosity among online learners. In their study, Tandy and Meacham (2009) posited that teachers did not necessarily have a deficit in their capacity to deploy instructional materials for learners' usage during digital teaching. Learners' learning characteristics vis-à-vis their specific learning or sensory disabilities influenced teachers' judgement on using instructional materials for virtual teaching.

Remarkably, since the submission by Tandy and Meacham (2009), the educational sector has witnessed significant changes with the influx of ICTs in education. However, how such changes have impacted the emergency-remote teaching, witnessed during the COVID-19 era, is yet unknown, especially regarding the teaching of natural sciences to LDHH. There is no doubt that tremendous advances and changes have been witnessed in the educational sector in the last decade, and the changes observed are due to the application and use of ICTs at various levels of education (Lersilp \& Lersilp, 2019; Maphalala \& Adigun, 2021; Jita \& Akintunde, 2021; Maiorana-Basas \& Pagliaro, 2014). Lamentably, despite the changes observed, issues of access and affordable Internet services have been a recurring challenge for e-teaching and learning (Maphalala \& Adigun, 2021). While Maphalala and Adigun (2021) acknowledged that the place of the Internet could not be over-emphasised, they posited that a reasonable percentage of the 
population of South Africa had access to the Internet. Jita and Munje (2020) added that although many South Africans had access to the Internet, citizens were faced with the high cost of Internet access, limited Internet speeds and limited penetration of broad-band Internet, which could be very frustrating and challenging for teachers, particularly during remote teaching.

\section{Statement of the problem}

Consensus exists on the importance of high-quality teaching of the natural sciences to learners, regardless of their hearing acuity. This consensus is based on the need to nurture and develop scientific reasoning and critical thinking skills in learners, including LDHH. Evidence of low scientific achievement and underperformance among South African high school learners abounds in the literature (Jita \& Munje, 2020). Lower levels of science engagement, achievement, and performance among LDHH are currently problems for all those concerned. Unfortunately, the events presented by COVID-19 may have worsened the state of engagement in and the acquisition of natural science knowledge and skills among South African LDHH. On the other hand, the application of technology in teaching and learning during lockdown may have positively influenced the teaching of natural sciences to LDHH.

Studies prior to the emergence of COVID-19 berated teachers' capacity to adopt and use ICTs and Internet-enabled technologies, such as Zoom, for the teaching of the natural sciences (Adigun, 2020; Andrews, 2017). Remarkably, however, a recent study emphasised the significance of ICTs in science teaching, and especially in practical laboratory work (Jita \& Munje, 2020). There is a paucity of research evidence on the exploration of teachers' perspectives on evolving issues in the teaching of the natural sciences via Zoom to $\mathrm{LDHH}$, especially during the COVID-19 lockdown in South Africa.

The Use and Gratification Theory (Blumler \& Katz, 1974) is the theoretical framework that oriented the study. The theory is an audience-based theoretical framework that presents an exposition between communication perspectives that explore the interactions between an individual and the media. In other words, Reimers et al. (2020) assert that an individual is believed to have the capacity to select media (Zoom) and content (natural science as a school subject) carefully, in order to fulfill personal or collective needs or wants. Earlier studies by Mehrad and Tajer (2016) engaged the Use-and-Gratification Theory to understand the interaction among persons in relation to the various perspectives of measured content.

Consequently, this study is anchored on the Use and Gratification Theory (Blumler \& Katz, 1974); and it explores teachers' perspectives on the evolving issues surrounding the teaching of natural sciences via Zoom to LDHH especially during the COVID-19 lockdown in South Africa - by trying to provide answers to the following critical questions:

1. Do the natural-science teachers in South Africa have the capacity to teach LDHH via Zoom? 
2. What are the challenges and successes of using Zoom for teaching the natural sciences to LDHH during the lockdown occasioned by COVID-19 in South Africa?

\section{The Methodology}

The nature of an exploratory study requires a systematic research approach of enquiry, in which the researcher has close interaction with the phenomenon under study (Creswell, 2013). Based on the characteristics of an exploratory study (Creswell, 2013), this study adopted the Interpretivist Paradigm, as well as a qualitative-descriptive research design, in order to explore some of the issues associated with emergency-remote teaching of natural sciences to deaf learners via Zoom during the lockdown occasioned by COVID-19 in South Africa.

A total of seven natural science teachers (4 males, 3 females) from four schools (Schools A, B, C and D) in the province of KwaZulu-Natal in South Africa were purposively selected for the study. The participants were purposively selected for this study, based on their availability and ongoing interaction with LDHH and the teaching of natural sciences via the Zoom to LDHH.

Due to the lockdown, the participants were reached by using a snowball approach. The participants for this study were purposively selected, based on the following criteria: They had to be teachers of $\mathrm{LDHH}$; they must have taught natural sciences to LDHH by using Zoom during the lockdown; and they must have been natural-science subject teachers in inclusive/special schools for more than five years.

To provide answers to the research questions, the data were collected by using one-on-one semi-structured interviews (Cohen et al., 2013). The interview schedule guide underwent content and face validity by two experts in science education - a research fellow and a life-science teacher in a school for the deaf.

The interviews were conducted via Zoom, in order to avoid compromising the safety of the researcher and the participants in terms of COVID-19. The interviews were conducted in English; and each session of the semi-structured Zoom interviews lasted for about 35 minutes.

The recorded one-on-one semi-structured interviews were scheduled with the selected participants, with the intent to elicit information from them about their capacities regarding the teaching of natural sciences to $\mathrm{LDHH}$ via Zoom, as well as their challenges and successes. The interview schedule covered the following key areas:

1. The extent to which natural-science teachers were supported by school administrators when teaching natural sciences via Zoom.

2. The nature of the support received by the participants to teach natural sciences to LDHH successfully by using Zoom during the lockdown.

3. Internet accessibility and technological infrastructure.

4. Staff development and training.

5. The challenges faced when teaching natural sciences to LDHH via Zoom.

6. The perceived successes of teaching natural sciences to LDHH by using Zoom. 


\section{Ethical considerations}

In accordance with the ethics of conducting research, the participants of this study were duly informed about the objectives of the study, and they subsequently gave their verbal and written consent to voluntarily participate in the study. The anonymity and the confidentiality of the participants' profiles and their responses were guaranteed. The study thus adhered strictly to all the ethics of social and humanity research, as indicated by the researcher's Institutional Review Board.

\section{The data analysis}

The recorded one-on-one semi-structured Zoom interviews were transcribed and coded. During the coding and the iterative processes of the transcribed interviews, the researcher ensured the anonymity of the participants. In other words, the participants were given pseudonym labels from NST1 to NST7. In accordance with Cohen et al. (2011), this study employed a thematic-content analysis to identify any recurring themes from the transcribed-Zoom interviews. The researcher identified some repetitive themes, which were used to address and provide responses to the research questions.

\section{The results}

The themes generated from the transcribed responses of the participants were organised into three core themes: namely, organisational and individual preparedness (Theme 1) that responded to research question 1; while difficulties with two-way teacher and learner interactions (Theme 2) and an uninterrupted learning model emerged as the theme (Theme 3) that responded to the research Question 2.

\section{Theme 1: Organisational and individual preparedness Sub-theme 1.1: Pedagogy and technology}

Teaching natural sciences for adequate understanding and practicability requires apt attention from the learners. In other words, science teachers in secondary schools believe that all the sense organs should be active for the efficient learning of scientific concepts (Adigun, 2020). In this study, the participants were of the view that teaching natural sciences, especially to LDHH via VCTs, was somewhat alien to the statutory face-to-face practices of teaching prior to the emergence of COVID-19. Lamentably, the emergence of COVID-19, which necessitated remote teaching, came as a shock to many science teachers of LDHH; and teachers' individual capacities to navigate the digital space, for the purpose of teaching natural science, became a laborious task. The findings revealed that prior to COVID-19, natural-science teachers, with the assistance of sign language interpreters, previously employed hands-on teaching strategies, in which LDHH were actively involved in the learning of scientific concepts in schools. The participants believed that many natural science teachers did not have the requisite capacity and the skill required to deliver scientific instruction to LDHH via Zoom effectively. Below are some of the comments from the study's participants. NST6 (female, from School D) commented that:

"Teaching science to learners with hearing loss is somehow challenging, when compared to that of their peers without deafness. Teaching them (LDHH) by using the Zoom was more of a challenging task for me. I had always struggled with these technologies (referring to phones and computers), even before the lockdown. The lockdown and the need to 
discharge my duties forced me into making use of my laptop for the purpose of teaching."

The participants acknowledged that teaching LDHH required extra effort and skills. Hence, they believed that engaging such learners using Zoom could present more difficulties for the teachers. The participants believed that they were constrained by e-teaching in comparison to the traditional face-to-face model of teaching. In support of this assertion, NST2 (male, from School A) said:

"Teaching natural sciences using the Zoom to deaf learners was not an easy task. We were not prepared for the task, but we were forced to accept the challenge posed by COVID-19. While teaching in the face-to-face classroom, teaching by mouthing (verbalisation of contents; sentence formation, etc.) could easily be seen by deaflearners, but having such an ability, while teaching via Zoom, was not guaranteed."

\section{Sub-theme 1.2: Training and re-training}

The issue of training for e-teaching was raised by the participants. Almost all of the participants stated that they had participated in little or no training for digital teaching prior to COVID-19. However, as the need to salvage the academic calendar arose, so too did the need to adopt remote teaching, while the lockdown persisted, so various trainings were hurriedly initiated to build the capacities of eteachers for the task ahead. NST3 (female, from School B) stated the following in this regard:

"Although, no substantive training was given on digital teaching for us (referring to teachers) prior to COVID-19, we were forced to go digital due to COVID-19. Although a crash training was done on the use of Zoom as a medium of instruction, as an individual, I was not really satisfied with the training."

As mentioned by NST3 (from School B), those who participated in the various training courses were not fully satisfied with the training received. The timing and mode of the training contributed towards their dissatisfaction with the process. In support of this assertion, NST7 (male, from School D) said:

"In order to build teachers' capacities to deploy technology for teaching, there was a short training course. Unfortunately, I would say the training was not comprehensive. The training itself was conducted virtually; and there was limited time to actually demonstrate what was taught."

In addition, NST7 (male, from School D) noted that:

"During the process of teaching my learners with Zoom, I came across many challenges, which necessitated me asking for assistance."

NST5 (male, from School C) noted that:

"The periods of lockdown and teaching are too demanding. Creating teaching content and digitalising the same is a challenging task. While I tried to ensure that deaf learners were adequately carried along, I had several issues with attaching my slides (PowerPoint). I am sure that if we had physical training in which I could ask questions, I think I may have done better with my e-teaching via the Zoom." 
NST6 (female, from School D) had this to say:

"I look forward to refreshing the memories of my learners when everything gets back to normal. This is because I am not sure that deaf learners had a full grasp of what I had taught them via Zoom."

\section{Theme 2: Difficulties with two-way teacher-learners' interactions Sub-theme 2.1: Communication/interaction challenges}

Uninterrupted two-way auditory-verbal communication remains a challenge, which individuals with hearing loss have faced over time. While some persons with hearing loss have the capacity to lip-read and decipher speech, based on the shape of the mouth in conjunction with various facial expressions, others depend solely on the use of assistive listening devices. Lamentably, participants in this study expressed their concerns about the difficulty in achieving effective two-way communication and interactions with back-end $\mathrm{LDHH}$, while teaching natural sciences via Zoom. Additionally, NST1 (female, from School A) remarked that:

"Teaching deaf learners using Zoom was challenging. Many times the learners had challenges with lip-reading, perhaps due to interruptions with Internet connections, either from me, or from them."

NST6 (female, from School D) said:

"Teaching natural science through Zoom was significantly different from how it was when we had the face-to-face teaching. There are many instructions, which I found difficult to pass across to the learners. I had little capacity to demonstrate, dramatize and/or to use pantomime, which usually aids effective teaching and learning in a physical classroom of deaflearners."

The participants believed that communication challenges forced them to speak and send typed messages at the same time, in order to corroborate what was being said, while the sign language interpreters did their job. However, this still posed a challenge because there was always a delay between when the sign language interpreter received the message and interpreted it for the participating LDHH. NST5 (male, from School C), said:

"I am sure that most deaf learners find it difficult to access all the needed information from me without a sign-language interpreter. While I speak for those who can lip-read or for those wearing assistive listening devices (hearing aids). I still type some of what I have said. This is because I want the learners to better understand the content being taught."

NST5 (male, from School C) also added:

"There was always a delay in the relaying of messages from the signlanguage interpreter, who was at another location, but who had also connected to the class via Zoom. The sign-language interpreter had to wait for me to finish speaking, while he/she then interpreted. As for me (NST5), this caused friction in the process of teaching via Zoom."

\section{Sub-theme 2.2: Issues with Internet connectivity}

E-teaching via Zoom cannot be achieved without the Internet. In other words, the Internet remains a channel through which users at different locations enjoy the advantages or services presented by VCTs, such as Zoom. Unfortunately, the 
participants in this study, as well as their learners (LDHH), indicated that they experienced some challenges with Internet connectivity at different times. Although the participants averred that the school administration provided them with the required amount of Internet data (megabytes), the network strength sometimes fluctuated during teaching, leading to delays in feedback.

NST4 (female, from School B) remarked:

"Teachers who participated in the online teaching were given Internet data, which enabled them to teach by using the Zoom technology. However, while I applaud the initiative of electronic teaching (eteaching), there were times when I experienced disruptions in the Internet services."

In support of NST4, NST7 (male from School D) had the following to say: "The disruption of Internet services during my time of teaching via Zoom could be very frustrating. One would have to wait for the Internet to reconnect. Sadly, such disruptions and reconnection sometimes caused delays in feedback for learners at different ends. It makes students ask me to repeat what I have said during the period when the Internet connection was lost."

NST2 (male, from School A), had the following to say about the situation: "While I enjoyed teaching my learners via Zoom, one would get frustrated when the Internet connection was lost. This is largely because it slowed down communication; and the learners at the other end, would have to reconnect with you (the teacher) at different times. Don't also forget the time frame with the sign-language interpreter. Furthermore, it might be the sign-language interpreter that lost the Internet connectivity. It is sad that a minute lost in Internet connectivity slows down the teaching process."

\section{Sub-theme 2.3: Difficulties using appropriate instructional materials}

Teaching science to learners requires that teachers display efficient use of real objects, as instructional materials. The application and use of real objects during the teaching of subjects, such as a natural science, provides LDHH with hands-on opportunities to interact with local, if not natural environments. Unfortunately, natural science teachers' effective use of real objects, as instructional materials, while engaging LDHH in real-time practical learning, was seemingly impossible while teaching via Zoom. Unlike practice in the pre-COVID-19 era, the participants noted that they had challenges in explaining scientific concepts to LDHH during their Zoom classes. In support of this assertion, below are some of the views of the participants.

NST1 (female, from School A) had this to say:

"My capacity to present instructional materials to LDHH during the Zoom classes, as indicated in my lesson notes, is almost impossible. Sometimes, I could only send the learners some pictures of the instructional objects; but I know that the learners themselves have a limited capacity to further check for more information on the brief 
introduction of the teaching aids, unless they receive support from their parents or their siblings."

The application and use of instructional materials for the teaching of natural science to LDHH via Zoom seemed to be a challenging task for the teachers. In addition to the assertion made by NST1, NST4 (female, from School B) stated:

"Before the lockdown, I usually started my teaching with my learners interacting with the instructional material. With it, after they have made the necessary observations on the instructional materials, the learners (LDHH) would make various comments on it, and then, I would introduce and start the lesson. Unfortunately, due to various factors, this strategy could not work for Zoom teaching."

Supporting the submission of NST4, NST7 (male, from School D) stated that:

"I only send the learner some pictures and videos of instructional materials. Sometimes I do send them the images before our online classes; but the learners hardly view or read whatever I sent to them prior to our online classes."

\section{Theme 3: An uninterrupted learning model}

\section{Sub-theme 3.1: Uninterrupted and continuous learning engagements}

While COVID-19 has led to the closure of schools and other public gatherings, many activities and functions, such as academic engagements, were halted, in order to stem the tide of COVID-19 infections and community transmission of the virus. Amazingly, schools have leveraged on the advantages presented by technologies, especially the VCTs, such as Zoom. Despite some challenges occasioned by COVID-19, the participants in this study expressed their satisfaction with the use of Zoom for the continuation of teaching and learning activities. For instance, NST5 (male, from School C) commented:

"I am quite happy with the electronic teaching. This is because it promotes continuous learning among our deaf learners."

NST2 (male, from School A) remarked:

"These learners (LDHH) were already struggling with their academics, especially in science subjects. If learning engagement were discontinued due to the lockdown, we (teachers) would have so many difficulties with them (LDHH), when physical classes resume. So, I like the fact that deaf learners were not left out in the digital teaching."

NST4 (female, from School B) also commented:

"I love the fact that my school engaged all the learners, especially the deaf, in online teaching. I can imagine the regression in knowledge gained, when the school would have resumed physical teaching."

\section{Sub-theme 3.2: Spurred interest in scientific and critical reasoning}

Digital learning may provide synchronous and asynchronous communication and promote independent learning. This study found that the participants believed that digital teaching during the lockdown would promote independent learning among deaf learners. In addition, issues around COVID-19, such as its mode of transmission, infection and symptoms, could further motivate and foster 
the interest of deaf learners in science subjects, especially the natural sciences. In support of this assertion, NST6 (female, from School D) communicated:

"Information about COVID-19 came as a surprise to our deaf learners. They were curious to understand the virus and its characteristics. Largely, I know that deaf learners had more interest in the natural sciences, especially with the emergence of COVID-19."

NST7 (male, from School D) commented:

"I would say that COVID-19 is a blessing in disguise. My learners would always want me to explain to them issues about the virus and how virulent it could be. NST7 further said: In fact, I get text or video calls from my learners almost every time, when they want clarification on the scientific nature of COVID-19."

NST3 (male, from School B) said that:

"Deaf learners showed so much interest in scientific concepts, particularly at this time of COVID-19. I can confirm that COVID-19 induced a great amount of curiosity and questioning in deaf learners. Issues of the wearing of facemasks, and social and physical distancing, led deaf learners to whom I teach natural science, to wanting to know more and clear their doubts about various information on COVID-19."

\section{Discussion}

Anchored on the Use-and-Gratification Theory (Blumler \& Katz, 1974) as the theoretical framework, this exploratory study was instituted to investigate the emergency-remote teaching of natural sciences to deaf learners by using Zoom during the pandemic. Three major themes were derived from the semi-structured, one-on-one Zoom-enabled interview with the seven participants, who were the teachers of natural sciences at four secondary schools in the province of KwaZuluNatal in South Africa. While COVID-19 led to the closure of physical schooling activities, several schools within South Africa and beyond adopted Internetenabled platforms for the continuation of teaching and learning activities (Tanga et al., 2021). Little research has been done in South Africa on the e-teaching capacity of teachers of deaf learners, hence, this study used a qualitative research design to assess teachers' capacity for teaching natural sciences to LDHH.

This study revealed that teachers' capacity for teaching natural sciences to LDHH via Zoom during the COVID-19 pandemic was limited. In other words, the participants were not able to exhibit their teaching dexterity to their utmost potential. Despite the fact that Zoom is widely used for video communication, especially in this period of COVID-19, and its potential to provide synchronous and asynchronous communication and instructional deliveries is proven (Alsadoon \& Turkestani, 2020; Lynn et al., 2020; Mpungose' 2020; Mukhopadhyay \& Mukhopadhyay, 2020; Osuagwu et al., 2017).

This study noted that the pedagogical skills and the e-teaching training received by the participants to actively teach natural sciences to LDHH via the Zoom platform were considered inadequate. Therefore, this current finding supported past studies (Adigun \& Nzima, 2020; James et al., 2019), which criticised the 
approaches to the teaching of natural sciences to deaf learners in the twenty-first century.

Adigun and Nzima (2020), Maphalala and Adigun (2021) and Lynn et al. (2020) noted that science teachers require continuous training, in order to sustain their capacity for online teaching and blended teaching. This study also found that the participants had challenges with uninterrupted two-way auditory-verbal communication. This finding was because an individual with deafness, or who is hard of hearing, requires a close-up view of the speaker's face and perhaps even their entire body. This close-up view of the speaker gives the deaf the opportunity to access non-verbal communication; and it contributes to the understanding of verbal instructions. Extant literature on deaf studies asserts that deaf learners require a full view of the speaker's face and body (Adigun, 2020a; Adigun \& Nzima, 2020; Alsadoon \& Turkestani 2020; Lynn et al. 2020; Ogundiran \& Olaosun, 2013; Pizzo, 2016).

This full view contributes to the level of understanding a deaf learner may have on the subject being taught (Adigun \& Nzima, 2020; Pizzo, 2016). Lamentably, some participants in this study were of the view that teaching via Zoom did not give them the ability to express themselves adequately, as they had been able to do when teaching face-to-face prior to the lockdown. Regrettably, this challenge suggests that teaching natural sciences via Zoom may prevent real-time feedback from $\mathrm{LDHH}$; and it may further negatively impact on these learners' satisfaction, as indicated by Alshawabkeh et al. (2021) and Schmitt and Eilderts (2018).

In today's world, the Internet has really impacted on daily interactions, especially since its infusion into teaching and learning activities. As indicated by Maphalala and Adigun (2021), Internet connectivity in South Africa has increased; and therefore, educational systems across all levels have largely adopted technology and infused the same into teaching and learning activities, especially during the COVID-19 pandemic. However, uninterrupted Internet access and fast Internet connection speeds remain a challenge experienced by many Internet users in the country (Maphalala \& Adigun, 2021).

The findings of this study showed that all the participants had access to the Internet for teaching natural sciences to LDHH via Zoom; but they had experienced some challenges with Internet connectivity and connection speeds. This current finding corroborates the earlier findings of Maphalala and Adigun (2021) and Schmitt and Eilderts (2018), who acknowledged the challenges associated with the use of Internet-enabled platforms for teaching and learning activities. Maphalala and Adigun (2021) reported that teachers were constantly constrained by erratic Internet access and connectivity while implementing eteaching. For efficient e-learning to take place, learners with hearing loss, who participate in VCT's enhanced teaching, require uninterrupted and fast Internet services. Improved Internet access would give such learners uninterrupted access to the speakers' faces and to the activities of the sign-language interpreters.

The effective usage of instructional material for teaching natural sciences to $\mathrm{LDHH}$ via Zoom was one of the major challenges faced by the study's 
participants. The participants of this study expressed their concerns about their inability to deploy effectively the real-object instruction needed for e-teaching, which was not a problem prior to COVID-19. Studies prior to the emergence of COVID-19 recommended the use of ICT-enabled platforms or blended learning for LDHH (Adigun, 2017). However, such studies did not express the teachers' potential to position instructional material effectively for e-teaching/e-learning.

The findings of this current study thus agreed with the research findings of Adigun (2020), Alshawabkeh et al. (2021), and Lynn et al. (2020), who brought the potential challenges faced by teachers during digital teaching for deaf learners to the fore. Schmitt and Eilderts (2018) suggested that during e-teaching, learners could easily lose touch with their online instructors and thus have less resilience for e-learning. Lynn et al. (2020) added that deaf learners exhibited e-learning fatigue, while Al Atiyat (2018) and Kanellopoulou et al. (2019) were concerned about learners' cognitive overload, when e-teachers were unable to make efficient use of instructional materials during synchronous teaching to young learners.

This study affirmed that the use of Zoom technology for teaching natural sciences to LDHH during the lockdowns not only informed uninterrupted and continuous teaching and learning engagements, but that asynchronous learning via Zoom also contributed to the established model for containing the spread of COVID-19. The findings of this study showed that teaching via Zoom fostered scientific inquisitiveness and critical reasoning among LDHH. The participants of this study also attested to the fact that teaching via Zoom promoted independent learning. This current finding was in line with the studies of Maphalala and Adigun (2021) and Tanga et al. (2020), who attested to the advantage of the cancellation of face-to-face teaching and embracing digital teaching, in order to curb the spread of this deadly coronavirus disease.

Alsadoon and Turkestani (2020) averred that the changes to the teaching model brought about by COVID-19 are somewhat of a blessing to the advocates of technology in education vis-à-vis the adoption of the fourth industrial revolution. Remarkably, this present study found that emergency-remote teaching of the natural sciences via Zoom to $\mathrm{LDHH}$ aroused their interest in the sciences. This finding thus validated the assertions of Adigun (2017), Mpungose' (2020), and Osuagwu et al. (2017).

\section{Conclusion}

The effects of lockdown in South Africa occasioned by COVID-19 have not only been negative, as the digitalisation of teaching and learning activities during the lockdown will remain one of the benefits to the educational system. Although a plethora of research evidence abounds on e-learning, few studies exist on the issues associated with e-teaching during the COVID-19 pandemic. Amongst the studies available on e-teaching, few or none have examined the implications of digital platforms on the teaching of the natural sciences to learners, who are deaf or hard-of-hearing. Using a qualitative research design, this study explored the emergency-remote teaching of natural sciences to deaf learners via Zoom in South Africa during the lockdown occasioned by COVID-19. 
Based on the findings derived from the semi-structured Zoom interviews, this study concludes that natural-science teachers, who teach LDHH via Zoom, have limited capacity to engage deaf learners in the digital classroom. In other words, the pedagogical structures and training required for such teaching experiences are grossly inadequate. Uninterrupted two-way auditory-verbal communication, Internet connectivity and connection speeds, as well as the difficulties faced by the participants, when using the instructional material required for efficient pedagogical delivery, are some of the major challenges faced while teaching natural sciences to LDHH via Zoom.

This study posits that teaching via Zoom, particularly during the pandemic, not only contributes to community safety against the deadly virus; but it also serves as a source of motivation for science learning and engagement for LDHH.

\section{Implications of the study}

The implications of this study highlight the need for improved teacher preparation. In other words, teacher-training institutions should update their curriculum to actively include the principles and practice of digital teaching. Such an endeavour would inform would-be teachers of the intricacies and challenges of online teaching and learning. In addition, in-service teachers need to receive regular training and re-training on the application of technology in teaching. Those teachers, who serve learners with disabilities, need to be given special attention when being trained on e-teaching approaches.

Such training should include the modalities that would promote the adequate visibility of teachers' facial expressions and the lip-reading potential of back-end deaf learners. The crux of e-teaching and e-learning is dependent on fast, continuous Internet facilities; thus, policies that would foster accessibility to the bandwidth required are needed for educational purposes; and they should be specially instituted.

\section{Limitations and suggestions for further studies}

This study used a qualitative-research design to explore the issues of the emergency-remote teaching of natural sciences to deaf learners via Zoom during the lockdown occasioned by COVID-19 in South Africa. The study collected the data by using a semi-structured Zoom interview with seven natural-science teachers of LDHH. A quantitative-research design approach would have presented an opportunity to collect the data from larger samples. Thus, the findings of this current study should be generalised with caution. In addition, while this study examined e-teaching via Zoom, the study focused solely on teachers; and no information was collected from the learners themselves (LDHH).

The researcher is aware that the information gathered from the learners and/or their parents or guardians might provide a more comprehensive result to directly inform policies and practice, in a manner that is beneficial to both natural-science teachers and deaf learners. This study did not explore an inter-provincial comparison of e-teaching via Zoom in South Africa, nor did it consider the state of teachers' psychological wellbeing when e-teaching during the lockdown. Based 
on the foregoing, it is suggested that future studies could adopt a quantitativeresearch design, in order to accommodate more research participants to ensure the generalisation of the findings, and thereby endeavour to bridge the gaps not closed by this current study.

\section{References}

Adigun, O. T. (2017). Effects of computer-assisted instruction and concept mapping on the academic achievement of students with hearing impairment in ecology in Ibadan, Oyo State, Nigeria. Journal of Issues and Practice in Education, 9(1), 123-146. https://journals.out.ac.tz/index.php/jipe/article/view/752

Adigun, O. T. (2020). Computer-assisted instruction, project-based learning and achievement of Deaf learners in Biology. Journal of E-Learning and Knowledge Society, 16(1), 23- 32. https://doi.org/10.20368/1971-8829/1135190

Adigun, O. T. (2020). Depressive symptomatology among in-school adolescents with impaired hearing. Humanities and Social Sciences Reviews, 8(2), 931-940. https://doi.org/10.18510/hssr.2020.82103

Adigun, O. T., \& Nzima, D. R. (2020). Digitalized vs. Interpreted biology instructions for deaf learners: Implication for a techno-society. Journal of Education and Social Research, 10(5): 265-272. https://doi.org/10.36941/jesr-2020-0104

Adigun, O. T., \& Nzima, D. R. (2021). The predictive influence of gender, onset of deafness and academic self-efficacy on attitude of deaf students towards Biology. South African Journal of Education, 41(2), 1-11. https:// doi.org/10.15700/saje.v41n2a1894

Al Atiyat, A. M. (2018). The effect of multi-media instructional design based on Sweller's theory on reducing cognitive load and developing scientific concepts among deaf primary students. Journal of Educational and Psychological Studies [JEPS], 12(4), 672685. https:// doi.org/10.24200/jeps.vol12iss4pp672-685

Alsadoon, E., \& Turkestani, M. (2020). Virtual classrooms for hearing-impaired students during the COVID-19 Pandemic. Romanian Journal for Multidimensional Education, 12(1), 1-8. https://doi.org/10.18662/rrem/12.1sup2/240

Alshawabkeh, A. A., Woolsey, M. L., \& Kharbat, F. F. (2021). Using online information technology for deaf students during COVID-19: A closer look from experience. Heliyon, 7(5), e06915. https://doi.org/10.1016/j.heliyon.2021.e06915

Andrews, F. J. (2017). Teaching Science to Deaf Students: Language and Literacy Considerations.

https://www.researchgate.net/publication/322701157_Teaching_Science_to_ Deaf_Students'_Language_and_Literacy_Considerations.

Blumler, J. G., \& Katz, E. (1974). Foreword. In J. G. Blumler and E. Katz (Eds.), The uses of mass communications: Current perspectives on gratifications research. Beverly HUls, CA: Sage.

Cohen, L., Manion, L., \& Morrison, K. (2013). Research methods in education (7th ed.). Routledge. https:// doi.org/10.4324/9780203720967

Creswell, J. W. (2013). Qualitative inquiry: Choosing among five approaches. Los Angeles, CA, 244.

Department of Basic Education. (2011). Integrated Strategic Planning Framework for Teacher Education and Development in South Africa, 2011-2025. Technical Report. Department of Basic Education. South Africa.

https://www.dhet.gov.za/Teacher\%20Education/Intergrated\%20Strategic\%20P lanning\%20Framework\%20for\%20Teacher\%20Education\%20and\%20Developme nt\%20In\%20South\%20Africa, \%2012\%20April\%202011.pdf 
James, A.A., Beni, S., \& Stears, M. (2019). Teaching science in the foundation phase: Where are the gaps and how are they accounted for?. South African Journal of Childhood Education, 9(1), a759. https://doi.org/10.4102/sajce.v9i1.759

Jita, T., \& Akintunde, M. (2021). Pre-service teachers' perceptions towards the Use of ICTs during Work-integrated Learning (WIL). In Society for Information Technology and Teacher Education International Conference (pp. 1441-1446). Association for the Advancement of Computing in Education (AACE). https://www.researchgate.net/publication/354239052_Preservice_Teachers'_Perceptions_towards_the_Use_of_ICTs_during_Workintegrated_Learning_WIL

Jita, T., \& Munje, P. N. (2020). Teaching science through information and communication technologies: 'enablers' and 'constraints'. The Independent Journal of Teaching and Learning, 15(2), 107-120. https:/ / hdl.handle.net/10520/ejc-jitl1-v15-n2-a9

Kanellopoulou, C., Kermanidis, K. L., \& Giannakoulopoulos, A. (2019). The dual-coding and multimedia learning theories: Film subtitles as a vocabulary-teaching tool. Education Sciences, 9(3), 210. https://doi.org/10.3390/educsci9030210

Lazzari, M., \& Baroni, F. (2020). Remote teaching for deaf pupils during the Covid-19 emergency. In 14th International Conference on E-Learning (pp. 170-174). IADIS Press. https://www.elearning-conf.org/wpcontent/uploads/2020/07/04_202007C024_S069.pdf

Lersilp, T., \& Lersilp, S. (2019). Use of information technology for communication and learning in secondary school students with a hearing disability. Education Sciences, 9(1), 57. https://doi.org/10.3390/educsci9010057

Lynn, M. A., Templeton, D. C., Ross, A. D., Gehret, A. U., Bida, M., Sanger, T. J., \& Pagano, T. (2020). Successes and challenges in teaching chemistry to deaf and hard-ofhearing students in the time of COVID-19. Journal of Chemical Education, 97(9), 3322-3326. https://doi.org/10.1021/acs.jchemed.0c00602

Madhesh, A. (2021). Full exclusion during COVID-19: Saudi Deaf education is an example. Heliyon, 7(3), e06536. https://doi.org/10.1016/j.heliyon.2021.e06536

Maiorana-Basas, M., \& Pagliaro, C. M. (2014). Technology use among adults who are deaf and hard of hearing: A national survey. Journal of Deaf Studies and Deaf Education, 19(3), 400-410. https://www.jstor.org/stable/43666294

Maphalala, M. C., \& Adigun, O. T. (2021). Academics' experiences of implementing elearning in a South African higher education institution. International Journal of Higher Education, 10(1), 1-13. https:// doi.org/10.5430/ijhe.v10n1p1

Maphalala, M. C., \& Adigun, O. T. (2021). COVID-19 and teacher preparation for learners with disabilities: The need for divergent praxis. Psychology and Education, 58(5), 5228-5240.

http://psychologyandeducation.net/pae/index.php/pae/article/view/6396

Mehrad, J., \& Tajer, P. (2016). Uses and gratification theory in connection with knowledge and information science: A proposed conceptual model. International Journal of Information Science and Management, 14(2), 1-14.

https://5.190.58.17/index.php/ijism/article/view/787/287

Mpungose, C. B. (2021). Lecturers' reflections on use of Zoom video conferencing technology for e-learning at a South African university in the context of coronavirus. African Identities, 1-17.

https://doi.org/10.1080/14725843.2021.1902268

Mukhopadhyay, B., \& Mukhopadhyay, B. K. (2020). COVID-19 and 'Zoom' for Remote Teaching: Enhancing Student Engagement. The Sentinel, Post-Editorial, 5th May. https://www.researchgate.net/profile/Boidurjo-Rick-

Mukhopadhyay/publication/340503926_Using_Zoom_to_Enhance_Student_En 
gagement_in_a_Virtual_Classroom/links/5eb13489299bf18b9595bb57/UsingZoom-to-Enhance-Student-Engagement-in-a-Virtual-Classroom.pdf

Ogundiran, O., \& Olaosun, O. A. (2013). Comparison of academic achievement between students with congenital and acquired deafness in a Nigerian College. Journal of Education and Practice, 4(23), 42-47. Available at https://citeseerx.ist.psu.edu/viewdoc/download?doi=10.1.1.965.298andrep=re p1andtype $=$ pdf.

Osuagwu, O., Ndigwe, C., Ihedigbo, C., Suleiman, U., \& Babatunde, O. (2017). Video conferencing: Most effective technology to run assemblies and meetings for large audience dispersed in distant locations: Is it feasible to deploy in Nigeria? West African Journal of Industrial and Academic Research, 17(1), 73-81. https://www.ajol.info/index.php/wajiar/article/view/156643

Pappas, M. A., Demertzi, E., Papagerasimou, Y., Koukianakis, L., Kouremenos, D., Loukidis, I., \& Drigas, A. S. (2018). E-Learning for deaf adults from a user-centered perspective. Education Sciences, 8(4)

206. https://doi.org/10.3390/educsci8040206

Pizzo, L. (2016). d/Deaf and Hard of hearing multilingual learners: The development of communication and language. Am. Ann. Deaf, 161, 17-32. https://www.jstor.org/stable/26235248

Reimers, F., Schleicher, A., Saavedra, J., \& Tuominen, S. (2020). Supporting the continuation of teaching and learning during the COVID-19

Pandemic. OECD, 1(1),

$1-38$. https://globaled.gse.harvard.edu/files/geii/files/supporting_the_continuation _of_teaching.pdf

Schmitt, E., \& Eilderts, L. (2018). Connected classrooms: Videoconferencing in TESOL teacher preparation. International Journal of Teaching and Learning in Higher Education, 30(2), 290-299. https://files.eric.ed.gov/fulltext/EJ1184995.pdf

Sooryamoorthy, R. (2020). Science, Development and Africa. In Science, Policy and Development in Africa: Challenges and Prospects (pp. 1-40). Cambridge: Cambridge University Press. https://doi.org/10.1017/9781108895804.002

Tandy, C., \& Meacham, M. (2009). Removing the barriers for students with disabilities: Accessible online and web-enhanced courses. Journal of Teaching in Social Work, 29(3), 313-328. https:// doi.org/10.1080/08841230903022118

Tanga, P., Ndhlovu, G. N., \& Tanga, M. (2020). Emergency-remote teaching and learning during Covid-19: A recipe for disaster for social work education in the Eastern Cape of South Africa. African Journal of Social Work, 10(3), 17-24. https://www.ajol.info/index.php/ajsw/article/view/202672 